\title{
The Office of Fusion Energy Recommendations on The Elmo Bumpy Torus Proof-of-Principle Experiment Site Selection
}

September 9, 1980

Published November 1980

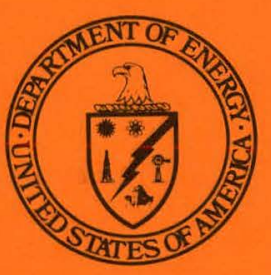

U.S. Department of Energy Office of Fusion Energy

Division of Mirror Confinement Systems 


\section{DISCLAIMER}

This report was prepared as an account of work sponsored by an agency of the United States Government. Neither the United States Government nor any agency Thereof, nor any of their employees, makes any warranty, express or implied, or assumes any legal liability or responsibility for the accuracy, completeness, or usefulness of any information, apparatus, product, or process disclosed, or represents that its use would not infringe privately owned rights. Reference herein to any specific commercial product, process, or service by trade name, trademark, manufacturer, or otherwise does not necessarily constitute or imply its endorsement, recommendation, or favoring by the United States Government or any agency thereof. The views and opinions of authors expressed herein do not necessarily state or reflect those of the United States Government or any agency thereof. 


\section{DISCLAIMER}

Portions of this document may be illegible in electronic image products. Images are produced from the best available original document. 
Printed in the United States of America

\section{Available from}

National Technical Information Service

U.S. Department of Commerce

5285 Port Royal Road

Springfield, VA 22161

NTIS price cudes

Printed Copy: $\quad \$ 6.00$

Microfiche Copy: $\$ 3.50$ 


\section{The Office of Fusion Energy}

\section{Recommendations on The Elmo Bumpy Torus Proof-of-Principle Experiment Site Selection}

September 9, 1980

Published November 1980
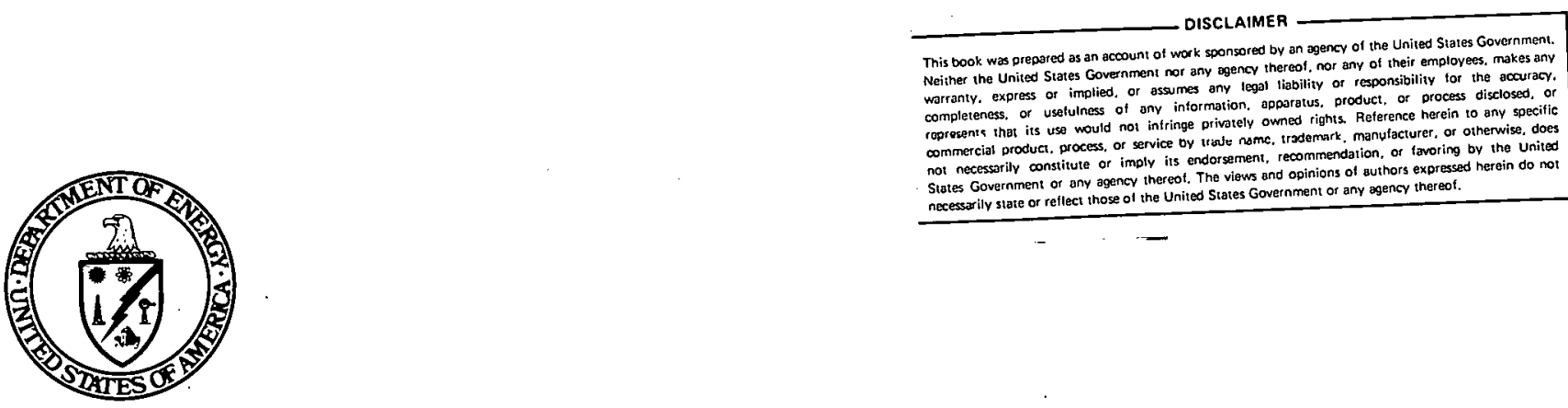

Prepared by:

U.S. Department of Energy

Office of Fusion Energy

Division of Mirror Confinement Systems

Washington, D.C. 20585 
PREFACE

This report was prepared by the Mirror Confinement Systems Division, Office of Fusion Energy (OFE), and sets forth the OFE recommendations for the Elmo Bumpy Torus Proof-of-Principle Experiment (EBT-P) site selection, in compliance with the terms of the Memorandum of Agreements on the initiation of the EBT-P project. The report was prepared between the dates of August 18, 1980, when the Oak Ridge National Laboratory (ORNL)/Union Carbide Source Evaluation Board Recommendations on EBT-P were received, and September 9, 1980, when this document was formally transmitted to the Office of Energy Research (ER) for further action.

Prompt approval of the OFE recommendations by ER and the Acting Under Secretary followed. On September 10, 1980, the White House was notified of the results and made a limited public announcement. An official U.S. Department of Energy press release was issued on September: $17,1980$.

The site chosen for the EBT-P facility is the privately owned Oak Ridge Valley Industrial Park in Oak Ridge, Tennessee. The prime contractor selected by the Oak Ridge National Laboratory for the design and construction of EBT-P is the McDonnel1 Douglas Astronautics Company of S.t. Louis, Missouri. The actions and decisions leading to these two selections are described in this report. The information will be of interest to students of the genre.

William R. Ellis, Director Division of Mirror Confinement Systems

Office of Fusion Energy Office of Energy Research 
TABLE OF CONTENTS

I. Executive Summary

II. EBT - Technical Background

III. EBT - Proof-of-Principle and Site Selection Background

IV. Discussion of Proposals and Union Carbide Recommendations

V. Office of Fusion Energy Analyst is of the Two Proposed Sites

VI. Office of Fusion Energy Site Recommendation
Page

1

2

4

8

11

18

APPENDICES

Appendix A: EBT-P Memorandum of Agreements

Appendix B: Action Memorandum to the Under Secretary

Appendix C: DOE Press Release 
The Office of Fusion Energy Recommendations On the EBT-P site Selection

\section{Executive Summary}

The selection process for the site of the Elmo Bumpy Torus Proof-of-Principle experiment (EBT-P), and the prime contractor to Oak Ridge National Laboratory (ORNL) for its construction, began formally in March 1979 with the signing of a Memorandum of Agreement (MOA) between the ORNL, the Office of Fusion Energy (OFE), and the Department of Energy's Oak Ridge Operations Office. This important document specified the detailed procurement and evaluation procedures to be followed, and defined the roles of industry and the signatories.

In April 1980, after approval by the Acting Under Secretary, a Request for Proposals was issued by ORNL for the design, construction, installation, testing, and operation of the EBT-P facility, based on a reference design generated as a result of competitive design studies conducted during the previous year. In compliance with the terms of the MOA, ORNL selected two proposals from those submitted, the best for an ORNL site $(Y-12)$ and the best for an alternate site. The winning proposal was submitted by McDonnell Douglas in both instances. The McDonnell Douglas alternate site is located in the Oak Ridge Valley Industrial Park (ORVIP), not far from Y-12. The ORNL recommendations were forwarded to OFE on August 18, 1980, for the final site determination. Since a single firm was the successful bidder for both sites, the DOE site selection does not affect the choice of contractor. However, OFE concurs in the ORNL selection of McDonnell Douglas as the prime contractor.

OFE has completed its analys is of the two sites and the contractor recommended by ORNL and recommends the non-Government ORVIP location as the site for the EBT-P facility.

The OFE recommendation for the ORVIP site is based on considerations of the overall best interests of the Government. The three primary factors considered were relative cost, schedule impact, and program flexibility and control. It is OFE's conclusion that the ORVIP site is the correct choice for a variety of reasons, detailed in the report.

The remainder of this report is structured as follows to provide background information and rationale for the procedures used and decisions made up to this time. Section II gives a brief history and technical description of the EBT concept. Section III provides the background of the EBT selection for a pronf-of-principle experiment and the evolution of the MOA. The Union Carbide evaluation of the proposals is reviewed in Section IV. Section V contains OFE's analysis of the two sites, and Section VI discusses the final OFE site recommendation. 


\section{EBT - Technical Background}

The Elmo Bumpy Torus (EBT) is an al ternate fusion confinement concept that combines some of the best features of both tokamaks and mirrors. The EBT concept grew out of experiments on electron cyclotron resonance heating (ECRH) in magnetic mirror confinement devices at the Oak Ridge National Laboratory. This research was begun with microwave power sources in about 1960. These ECRH plasmas had many interesting features, two of which will be mentioned here. The first is that a hot, energetic electron population was created by the ECRH. Hot electrons, some of whose energies were in the several million electron volt range, were observed to form "rings" or "doughnut-shaped" annuli with a high energy density, or "beta". The second feature was that the lifetime of the core plasma was ultimately limited by particle loss out the ends of the mirror. A possible cure for the end-loss problem was to connect many mirror devices together in a circle. The magnetic field lines would then close on themselves to form a torus, but because the field lines would al ternately contract and expand. the torus would be "bumpy".

In such a device the particle loss from one cell would become a particle feed to adjacent cells. The difficulty with the bumpy torus was that, while the plasma had an equilibrium, it was theoretically unstable. The magnetic field could not hold the plasma very long. To overcome this difficulty it was proposed to use the energy density in the electron rings to modify the magnetic field in a favorable way.

To test these conjectures a new toroidal device, the EBT-I, was built at ORNL and operated in 1973. In this device, the techniques developed in the ECRH mirror work, such as magnetic coil construction and microwave power distribution, were used. The new device indeed demonstrated that electron rings were formed, that the plasma confined within the rings was stable, and that the confinement time was now determined by cross-field diffusion.

In the years that followed, the EBT program gained strength from intensive efforts in the experimental, theoretical, and technological areas. The following technical conclusions have been reached:

- The high-beta annuli do produce a macroscopically stable toroidal plasma with parameters $\mathrm{n} \sim 1-2 \times 10^{12} \mathrm{~cm}^{-3}, T \sim 300-600 \mathrm{eV}$, $T_{i} \sim 50-100 \mathrm{eV}$, and $\tau \sim 3-8 \mathrm{msec}$. This is remmarkable performance for a device of such smalf dimensions and low heating power.

- True steady-state operation is obtained in EBT ( $\left.t>10^{4} \mathrm{sec}\right)$, plasmawall equilibrium is established, and long-pulse physics and technology issues are addressed as part of the basic research program.

- Closure of magnetic field lines, which is required for good confinement, can be readily obtained by a combination of careful construction and global field correction techniques. 
- Impurity levels in the toroidal core plasma are very low $\left(n_{7} / n_{0}\right.$ $\sim 10^{-3}-10^{-4}$ for carbon and aluminum). In addition, the pooriy confined surface plasma appears to act as a "natural" divertor and effectively screens the toroidal plasma from incident impurities.

- Plasmas can be produced in the "collisionless regime" $\nu / \Omega<1$, where $\nu$ is the collision frequency and $\Omega$ is the poloidal precessicnal drift frequency, and in this regime electron energy confinement time increases with temperature. EBT-I operates in the same collisionality regime as is required for a reactor.

- The best fit to experimental EBT data indicates the electron diffusion is classical and, with allowance for a non-Maxwellian ion distribution, the ion diffusion is also classical. Similar ion and electron behavior is expected in future devices.

- The ambipolar electric field is found to be negative (points radially inward), azimuthally symmetric, with a potential well of magnitude e $\phi / k T_{i} \sim 1$ (where $T_{i}$ is the higher energy component of the ion distribution).

Concommitant with these investigations, a microwave tube manufacturer, Varian Associates, developed with DOE funding a new intense microwave power source, the high-power gyrotron. This important technological advance increased confidence that the microwave sources required for more advanced EBT machines could also be developed. The EBT-I experiment was upgraded in 1978 to use the new higher power, higher frequency gyrotron ( $28 \mathrm{Ghz}$ instead of $18 \mathrm{GHz}$ klystrons). The upgrade, which uses a higher magnetic field ( $10 \mathrm{kG}$ instead of $6 \mathrm{kG}$ ), is called Elmo Bumpy Torus-Scale (EBT-S). The higher field capability had been built into EBT-I from the beginning. EBT can be operated as either EBT-I or EBT-S, depending on which microwave source is used, with little lost down-time for the changeover. EBT-S has operated with $60 \mathrm{kw}$ output from the $28 \mathrm{GHz}$ gyrotron, and other developmental tubes have recently been tested as high as $200 \mathrm{kw}, \mathrm{cw}$.

At the present time, detailed self-consistent data sets, taken together with results that have emerged from an ever-expanding theoretical program, have shown good agreement between theory and experiment, increasing confidence that the basic principles of EBT operation are well understood. Qualitative understanding has been gained of the detailed ECRH core heating, including the wall reflection, propagation and absorption characteristics of the different wave modes. The experimentally measured tail of the ion energy distribution is now understood to be a natural consequence of the resonant diffusive neoclassical loss mechanism, and transport codes predict fully classical, stable, collisionless regimes for EBT devices all the way to a reactor.

Studies of the potential of EBT as a fusion reactor have demonstrated a number of other very attractive attributes, such as continuous operation, simple construction, extrapolable technology requirements, and convenient maintenance techniques. As a result of the confidence generated by these efforts in various areas, studies of a successor device to EBT-I/S were begun as early as 1975. The logical next-step device for this concept is a proof-of-principle experiment, as will be discussed in more detail in the following sections. This next- 
step device has been designated EBT-P. In summary, EBT-P is intended to be a flexible hydrogen fueled machine with most of the crucial dimensionless parameters (ring beta, collisionality, etc.) in the reactor regime. The proposed device will be superconducting and steady state, also as in a reactor, and will address the critical issues of physics and technology scaling for the concept.

\section{EBT - Proof-of-Principle and Site Selection Background}

\section{A. Alternate Concepts Policies}

In early 1978 the Ad Hoc Experts Committee on Fusion, chaired by Dr. John S. Foster, Jr., reviewed the fusion program at the request of Dr. John M. Deutch, then Director of Energy Research. One of the Foster Committee recommendations was to strengthen alternatives to tokamaks and mirrors. The Foster Committep Report (DOE/ER-0008) recommended that "the most promising alternate concepts should be chosen" for support in a more focused development program. Later in 1978, DOE issued the Department of Energy Policy for Fusion Energy (DOE/ER0018), which placed increased emphasis on alternate concept development: "It is necessary that we choose those alternative concepts which show the most promise of providing significant advantages over tokamaks, and devote available resources to them." The policy statement further suggested that promising alternate concepts should be capable of comparisons with tokamaks and mirrors by the middle $1980^{\prime} \mathrm{s}$, in order to impact program decisions made in that time frame.

The DOE policy strategy requires that the promising alternate concepts be developed in an aggressive fashion if they are to offer any real options to future decision makers. In order to make meaningful comparisons between tokamaks, mirrors, and alternate concepts, it is necessary to extend considerably the scientific and technological data bases of the selected concepts toward the reactor regime via significant experimental tests. These significant tests have been designated as proof-of-principle experiments. A proof-of-principle experiment for an alternate concept can be considered in some ways as the scientific equivalent of the Princeton Large Torus (PLT) experiment in the tokamak program, although the analogy is not exact. Most of the important dimensionless plasma parameters (collisionality, etc.) should be in or near the reactor regime. The plasma density, temperature, and confinement parameter $n \tau$ should have significantly large values. Also, because the proof-of-principle device will probably be one of a kind, it should have built-in flexibility and upgrade potential. The experiment should be capable of resolving the outstanding physics and technology issues in such a way that methods of extrapolating to the next-step device -- a large D-T burning machine -- are clear and plausible. Thus, in the same spirit that PLT removed any doubts that may have lingered about the technical viability of proceeding with TFTR in the tokamak program, so a proof-ofprinciple experiment should play a similar role for alternate fusion concepts.

In response to DOE's fusion policy, the Office of Fusion Energy (OFE) formed a Concept Review Committee to evaluate all alternate concepts from the perspective of a possible proof-of-principle test. A week-long review meeting, publicly announced in the Federal Register, was held in October 1978 in Germantown to consider which, if any, of the alternate concepts were ready for an accelerated 
program, based upon physics accomplishments, technical promise, and reactor potential. The DOE Concept Review Committee, consisting of representatives from the Office of Fusion Energy, the Office of Energy Research (ER), and the Office of the Assistant Secretary for Energy Technology (ET), was assisted by 18 technical consultants selected from leading universities having fusion programs, national laboratories, foreign fusion research centers, and U.S. utilities. The Concept Review Committee and its consultants overwhelmingly chose a single concept, $5 B T$, as being ready for an accelerated development, and the Committee unanimously recommended "an aggressive, systematic course of action leading to an EBT proof-of-principle experiment, including expansion of the existing theoretical, experimental, and reactor study programs, initiation of design activities for an EBT proof-of-principle experiment, and support for the necessary gyrotron microwave tube development." DOE senior management (OFE, ET, ER) concurred formally in the Committee's recommendations, and Dr. Deutch responded that "enhanced development of the EBT concept will have a beneficial broadening effect on the (fusion) program and is in accordance with the recommendations of the Foster Committee, and my recent Fusion Policy Address."

\section{B. Next Steps}

The effect of the alternate concept evaluation was to identify EBT as tive leading alternative to the principal approaches (i.e. tokamaks and mirrors). Both ER and OFE wanted the opportunity presented by the EBT selection to 2 used to involve industry in a more significant way earlier in the program than had occurred, for example, with tokamaks and mirrors. Dr. Deutch provided the following specific guidance: 1) contractor(s) for the conceptual design phase should be competitively selected, 2) the contractor selection for construction should take into consideration performance in the conceptual design phase, 3 ) non-Government locations should be given serious consideration for the site. In applying these guidelines, OFE also had to take into consideration the needs of the base EBT program at ORNL and DOE policy, which prohibits direct competition between national laboratories and industry. The procurement procedures and participant roles that were developed for EBT-P were formalized in a Memorandum of Agreement (MOA) signed in March 1979 by the Oak Ridge National Laboratory and two organizations within DOE, the Office of Fusion Energy and the Oak Ridge Operations Office (ORO). The MOA established ORNL as the lead EBT laboratory and directed, among other things, that industrial participation be actively sought in all phases of the EBT-P project, including operation. Phase I would consist of project definition studies for the new experiment. Phase II would consist of actual design and construction of the device, and Phase III would be the operation or experimental program. Industrial participation was to be initiated through a competitive proposal process that would lead to the selection of a qualified group (or groups) to work with ORNL.

Another aspect of the MOA concerned the site selection process. The industrial teams that proposed to build EBT-P were obligated to propose construction at the Government-owned ORNL site $(Y-12)$. At their option, they could also propose to build the device at one or more aiternate sites. 
The key roles were summarized in the MOA as follows:

$\underline{\text { ORNL }}$

"ORNL will coordinate the overall EBT program and will be responsible for the management of EBT-P and EBT-S such that fusion program objectives and constraints are satisfied. ORNL will conduct the procurement process to enable the expeditious selection of, and award of an ORNL contract to, the industrial participant (IP)."

$\underline{O R O}$

"ORO will provide the formal administrative reviews and approvals for the procurement decisions and will participate in the technical and managerial decisions in anticipation of field office project management responsibilities in arrordance with MnF policy. Following project approval, ORO will take the lead in developing a comprehens ive Project Management Plan."

$\underline{\text { OFE }}$

"OFE wi!l provide overall programmatic guidance, project overview and definition, and funding for EBT-P and other components of the EBT program. Authorized OFE staff will have the opportunity to participate in related ORNL EBT-P selection activities. The establishment of the final reference design and the site selection decision will be made by OFE."

To begin Phase I, a Commerce Business Daily announcement in April 1979 invited all interested industrial groups to submit proposals for project definition studies. In June 1979 four different teams submitted competitive proposals and each was awarded a firm fixed price contract for a period of four months to prepare a study. These teams were headed by the firms of EBASCO, Grumman Aerospace, McDonne11 Douglas Astronautics, and Westinghouse.

Project definition studies were submitted on October 29, 1979. These four independent studies, together with a fifth study produced by ORNL, were discussed and refined in a series of public meetings at ORNL involving all interested parties. The task was made easier because all five studies had proposed generally similar devices and project goals. From these meetings a single, consolidated reference design emerged, which is described in ORNL/TM-7191, "The EBT-P Proposed Reference Design."

A review committee convened by DOE, with Dr. Robert Conn of UCLA as chairman; gathered in Germantown in January 1980 to consider the EBT-P project and EBT program developments since the time of the alternate concepts review. That meeting was attended by representatives from each of the four industrial teams, as well as by ORNL representatives. The Committee report recommended approval for EBT-P but with some qualifications. One was that the scope be broadened to address the question of plasma stability at higher values of plasma energy density, or "core beta". Another was that a subsequent panel examine progress theoretical and experimental - about one year later before final authorization is given to proceed with construction. On the basis of these recommendations a Final Reference Design was formulated and approved by OFE. 
A draft version of the Request for Proposals (RFP) for Phase II was released for review and comment in February 1980. In April 1980, approval was obtained from the Acting Under Secretary to issue the official RFP for Phase II. In accordance with the terms of the MOA, the Phase II RFP was issued only to the four firms who had participated in the Phase I project definition studies. The Final Reference Design was used by all four offerors as the basis for their proposals. Its purpose was to provide a common denominator for evaluating the proposals, and not to provide the final word on EBT-P design.

Some of the features of the EBT-P procurement are as follows:

1. The RFP for Phases II and III essentially calls for a turnkey job in that the awardee will be required to design, procure, fabricate, construct, install, test, and start up, and to play a significant role in the operation of both the facility and the device.

2. The selection includes the major subcontractors listed by the offeror. They are part of the offeror's team and as such cannot be replaced except under extraordinary circumstances.

3. Although the contract will be a cost-plus fixed fee (CPFF) type, the RFP requires that firm fixed price competitive contracting be used wherever possible. The magnet designer/fabricator, al though part of the selected team under the principal contract, will be required to negotiate a separate firm fixed price contract for the production of the magnet set.

4. Following the terms of the MOA, ORNL is charged to select and recommend two proposals, the best proposal at the $Y-12$ (ORNL) site, and the best proposal at a different site. DOE will select the final site and in so doing will automatically select the proposing.firm.

5. The selection of the Phase II contractor automatically selects him as the Phase'III operator unless extraordinary circumstances intervene, but future contract negatiations will be necessary to define his precise role in Phase III operations.

On May 30, 1980, the four offerors submitted their proposals to ORNL. An evaluation team composed of Union Carbide personnel evaluated these proposals in June and July. One or more ex officio (non-voting) team members from OFE and/or ORO attended each team meeting, as discussed in more detail in the following section.

The final report of -the Union Carbide evaluation team, and ORO's comments on the Carbide recommendations, were received by OFE in Germantown on August 18, 1980. The results of the Carbide evaluation were not announced publicly, pending the final site approval by DOE. 
IV. Discussion of Proposals, and Union Carbide Recommendations

In response to the Request for Proposals, proposals were received from four firms. These firms and their subcontractors were:

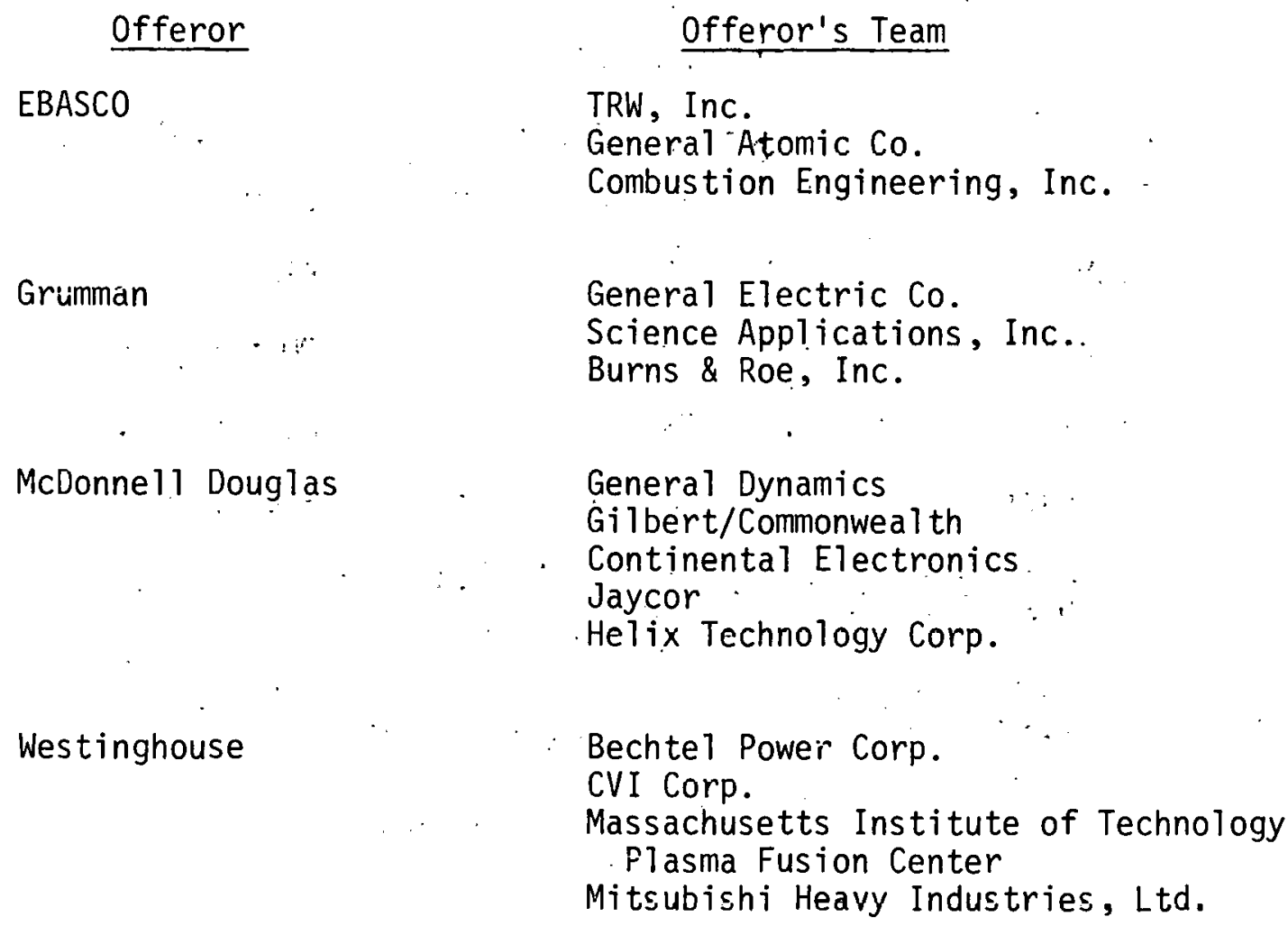

In evaluating the proposals, considerable attention was given to the subcontractors' roles and participation because of their responsibilities as an integral part of each prospective tcam or consortium.

A total of ten proposals was submitted by the four firms. These proposals included one each for the $\mathrm{Y}-12$ (ORNL) Government site; one each for a nonGovernment site in the Oak Ridge Valley Industrial Park (ORVIP) located in the town of Oak Ridge near $\mathrm{Y}-12$; one in Capistrano, CA; and one in Cheswick, PA. If one assigns a number to each proposal, it is convenient to group them into three site categories as follows (alphabetical listing in each group):

\section{Distribution of Proposals by Site}

\section{$\underline{Y-12}$}

1. Ebasco

2. Grumman

3. McDonnell Douglas

4. Westinghouse
ORVIP

5. Ebasco

6. Grumman

7. McDonnell Douglas

8. Westinghouse
Elsewhere

9. Ebasco (Capistrano, CA)

10. Westinghouse

(Cheswick, PA) 
A number of individuals were involved in evaluating the EBT-P proposals. The final recommendations were prepared by the team voting members who constituted the Union Carbide/ORNL Source Evaluation Board (hereinafter referred to as the Board):

\section{$\because$ EBT-P Board}

Name

J. A. Blair

Organization

Pürchasing, UCC-ND

A. L. Boch

FED - ORNL

G. R. Haste

FED - ORNL.

C. L. Hedrick

FED - ORNL

P. B. Thompson

UCC-ND Engineering
Specialty

Contract Administrator

EBT-P Project Manager

EBT Experimentalist

EBT Theorist

Engineering Mc.nager

(UCC-ND = Union Carbide Corporation - Nuclear Division; FED = Fusion Energy Division, ORNL)

The Board members were aided in their deliberations by a group of non-voting advisors, consultants, and ex offiçio members, who were:

\section{Ex Officio Members (AII DOE)}

\section{$\underline{O R O}$}

P. D. Dayton

K. T. Dziedizic

M. J. Gouge

J. J. King

L. V. Price

J. K. Williams
OFE

W. R. Ellis

E. E. Kintner

j. M. Turner

ER

R. A. Zich

$\therefore$ EBT-P Evaluation Team Advjsors

K. U. Bérkau

M. Harris

H. C. Webb

L. A. Berry

O. B. Morgan

J. Shetfield

M. W. Rosenthal
(UCC-ND, Purchasing)

(UCC-ND, Purchasing)

(UCC-ND, Purchasing)

(FED - ORNL)

(FED - ORNL)

(FEU - UKNL)

(UCC-ND, ORNL) 
EBT-P Evaluation Team Consultants (Device \& Facility)
W. R. Hamilton
R. A. Michelotti
T. J. McManamy'
W. H. Power
D. B. Campbe11
W. M. Fletcher
J. K. Ballou
S. P. Kinsey
H. O. Eason
T. L. White
J. D. Stout
(UCC-ND, Eng.)
(UCC-ND, Eng.)
(UCC-ND, Eng.)
(UCC-ND, Eng.)
(UCC-ND, Eng.)
(UCC-ND, Eng.)
(FED - ORNL)
(UCC-ND, Eng.)
(FED - ORNL)
(FED - ORNL)
(UCC-ND, Eng.)

\section{EBT-P Tean Cost Evaluation Commttee}
H. C. McCurdy
R. A. Brown
T. J. McManamy
J. D. Stout
W. R. Hamilton
W. M. Fletcher
E. Faulkner
K. E. Moore
J. M. Gregg

(Chairman; FED - ORNL)
(UCC-ND, Eng.)
(UCC-ND, Eng.)
(UCC-ND, Eng.)
(UCC-ND, Eng.)
(UCC-ND, Eng.)
(UCC-ND, Auditing)
(UCC-ND, Auditing)
(UCC-ND, Auditing)

In spite of the large number of participants, and several months of time involved, confidentiality of information in this selection process has been effectively mainlained.

Written discussions with each of the four firms submitting proposals were initiated early in the selection process. Deficiencies in the cost and pricing data were analyzed by the Board's cost committee, who made adjustments to the offerors' cost estimates to provide a common pricing structure. Simultaneous with this activity, the Board, with assistance from its consultants, developed technical questions that were submitted to the offerors for clarification. Site visits of a fact-finding nature were made to each offeror's corporate headquarters by a group consisting of the Board and four non-voting members ( $L$. A. Berry, ORNL; L. K. Price, ORO; W. R. Ellis, OFE; and J. M. Turner, OFE).

In addition to these corporate visits, a team composed of J. D. Stout (UCC-ND Engineering), D. B. Campbell (UCC-ND Engineering), and J. B. Clendenen (UCC.ND Purchasing) visited the two proposed alternate sites remotely located from Oak Ridge to view and evaluate their adequacy and suitability.

\section{Proposal Rankings and Recommendations}

The Board used two categories to rate the proposals: technical merit and cost. The cost estimates were adjusted by the cost committee, to arrive at the probable cost to the Government. The proposals were for CPFF contracts, as specified in the RFP. The primary factor in the evaluations was the technical merit of the proposals, with cost data to be used only in case the scoring was close. 
As it turned out, the choice of a winner was clear-cut on both counts. A single offeror, McDonnell Douglas, achieved the highest score on technical merit for both the $\bar{Y}-12$ site and the alternate site categories and, in addition, after cost adjustments and donations had been taken into account, proposed the lowest probable cost to the Government for both sites. This produced the highly desirable circumstance that the technicaliy best proposal was submitted by the lowest bidder in the case of both the $Y-12$ site and the alternate site; and further, the same firm was the successful proposer in both instances. OFE's site selection, therefore, will not affect the choice of contractor.

The Board's report, which describes the technical scoring and ranking of the ten EBT-P proposals in detail, including cost adjustments, is a business-confidential document and will not be further reproduced here. However, it is worth repeating that DOE personnel attended all of the Board's meetings. The purpose of the DOE presence in these meetings was to assure that proper procedures were followed, and to counter any appearance of conflict of interest by Union Carbide in this procurement action. As a result, OFE and ORO are able to comment authoritatively on all aspects of the proposal evaluations. It is the opinion of all DOE participants that the Union Carbide Board, under the able chairmanship of James $A$. Blair, did a very professional and objective job in handling the EBT-P proposal evaluations. The Oak Ridge Operations Office, in its review of the Board's report, commented "ORO participated in the Carbide selection process in great detail, including representation at all Board meetings and visits to the proposers. Based on this participation and our own review of the proposals, we are convinced that the selections were made in a thorough, competent, and unbiased manner, and the proper conclusions were reached."

In summary, OFE fully supports the recommendations and conclusions reached by the Board in its report. The main points may be summarized as follows: 1) considering technical merit and probable cost-effectiveness, the selection of McDonnel1 Douglas for award of the contract is in the best interests of both DOE and the EBT-P program; and 2) the two sites recommended to the Government for the EBT-P facility are the $\mathrm{Y}-12$ (ORNL) site and the Oak Ridge Valley Industrial Park (ORVIP) site, both proposed by McDonnell Douglas.

\section{OFE Analysis of the Two Proposed Sites}

The basic guidance provided by the Office of Fusion Energy was that the site finally selected for EBT-P would be the site which was in the overall best interests of the Government, all factors considered. To provide further guidance to the offerors on what factors would be considered by OFE in selecting the site, three considerations were developed and published in the RFP. These considerations, restated in expanded form, are: 


\section{OFE Site Selection Considerations}

1. Relative Cost to the Government

Favorable consideration will be given to the lower probable cost to the Government during Phases II and III, all other factors being equal. Such costs will include all near term and long term items, donations, cost sharing arrangements and other financial contributions.

2. Potential Impact on Schedule

The proposed timetables will be evaluated considering the impact of an accelerated or retarded schedule on project costs. Favorable consideration will be given for site-specific factors which bring EBT-P into operation at the earliest possible date without significant adverse cost impacts.

3. Efficacy and Viability of the Proposed Arrangement and the Interface With the EBT Program

The site must be acceptable programmatically and environmentally. The proposed project management structure, technical leadership, and staff responsibilities for Phases II and III will be important considerations. Since critical design information for EBT-P must be obtained from EBT-S during the EBT-P construction years, strong weight will be given to interfacing arrangements with $C B T-S$ and other EBT program elements that maximize good communications. Means must exist for interfacing and interacting with all facets of the EBT program.

Under the terms of the MOA and the RFP, DOE will limit its site determination to the two selections made by the Board. As discussed in Section IV, these sites are the Government reservation at $\mathrm{Y}-12$ and the nearby nak Ridge Valley Industrial Park (ORVIP) site in the town of Oak Ridge.

Site Descriptions

The $\mathrm{Y}-12$ site specified in the RFP is located in the Fusion Energy Division building which contains the EBT-S and ISX-B fusion experiments. This same building houses various fusion technology facilitiës,' such as neutral beam test stands, and offices for scientific, management, and support stáff. Other'devices not managed by the fusion program, such as the 86 -inch cyclotron that produces rare medical isotopes, are also located in this building. Computer, utility, and shop services are available at thijs site.:

The ORVIP site is a tract of land adjacent to (across the street from) the Government Y-12 site. (The ORVIP site is sometimes humorous ly referred to as "Y-13".) ORVIP is owned and being developed by the City of Oak Ridge as part of the City's efforts to increase its industrial tax base. The City's efforts are in line with the Federal Government's policy of encouraging a greater degree of financial self-sufficiency in Oak Ridge, with the intent of reducing federal support in lieu of taxes. The City, as part of its development of ORVIP, will provide primary utilities (water and power) to the site. Paved access roads 
already exist. McDonnell Douglas has an option from the City to purchase their proposed alternate site (about 11 acres) in ORVIP. Other potential sites in ORVIP are also available if, for example, a corner location is preferred. In the McDonnell Douglas proposal, the firm will own both the 1 and and the facility. The firm would use them in the performance of their contract, and would recover allowable costs in the same manner as any other private contractor. The RFP included a statement that provision must be made in the alternate site case for removal of the EBT-P prime contractor if performance is not satisfactory. The McDonnell Douglas proposal contains such a provision.

These two sites have been evaluated by OFE according to the three site considerations stated above. The results are summarized below.

\section{Relative Cost to the Government}

Costs to the Government have been analyzed in three categories: construction costs, operating budgets for research and development, and experimental operation (Phase III).

\section{a. Construction}

The estimated costs for construction, as adjusted by the ORNL cost committee, are:

Adjusted Construction Costs

(escalated $\$$, in millions, no contingency)

\begin{tabular}{|c|c|c|}
\hline & $y-12$ Site & ORVIP Site \\
\hline Device Design \& Construction & 51.6 & 55.6 \\
\hline Facility Design \& Construction & 7.2 & 2.6 \\
\hline Fee & 7.6 & 7.9 \\
\hline & $6 \kappa, 4$ & 66.1 \\
\hline
\end{tabular}

The device costs are higher for ORVIP because of the requirement to provide two additional gyrotrons with associated power supples and hardware and because the ORVIP site would require the installation of a demineralized water supply system and cooling tower and instrument air system already available to $Y-12$. Facility costs to the Government are considerably lower at. the ORVIP site because of donations made by the offeror. McDonnell Douglas will provide the land (approximately 11 acres), the building, and all facility appurtenances except the device enclosure. The McDonnel1 Douglas estimate for their contributions is $\$ 9.9$ million; the ORNL adjusted cost for this contribution is $\$ 8.3$ million.

In the case of the $Y-12$ site, the McDonnell Douglas facility cost estimate includes a significant amount of demolition work and compares closely with earlier ORNL estimates. 
These estimates contain considerable uncertainty and caution should be exercised not to use them as the basis for a project estimate. A relative comparison, however, is appropriate and indicates that the Phase II costs are likely to be about the same, regardless of site.

An important point to note is that if OFE should decide it is programmaticaliy desirable to shut down EBT-S and to move the two EBT-S gyrotrons and their power supplies over to the ORVIP sitc, a viable option for the program, construction costs at the ORVIP site would be somewhat below those at $Y-12$.

The $\$ 62.6$ million in the DOE Schedule 44 corresponds to the $\$ 66.4$ million figure above. However, the cautionary note that such a comparison might be misleading is exemplified by the fact that the McDonnell Douglas estimate was the lowest of the four cost estimates submitted for an essentially identical scope of work. The highest estimate was $\$ 89.7 \mathrm{million}$ and the average was $\$ 76.8 \mathrm{million}(\mathrm{Y}-12$ site case). The unadjusted cost proposals ranged from $\$ 56.4$ to $\$ 82.9$ milition with an average of $\$ 74.1$ million. The message from all this is that ar in-depth cost estimate review is needed among DOE, ORNL, and McDonnell Douglas as soon as practical after the contractor selection is announced; and it would be premature to attempt to adjust the Schedule 44 cost estimate before then.

b. Research and Development Support

The operating budget research and development support estimates were not adjusted by the ORNL cost committee. During the evaluation, it became apparent that a wide variance existed in the interpretation 'given to the level of effort for this' task by the different offerors. The McDonnel1'Douglas estimates for the research and development support at the $Y-12$ site are close to the ORNL estimates and differ from those for the ORVIP site, as shown be low.

Research and Uevelopment Support - Uperating Budgets (unadjusted, '\$K)

WBS Item

Technology Development

Inventory/Spares

Physics Support

Diagnostics and DAS

Prototypes/Verification Testing

Uperations Support

Improvements

TOTAL

McDonnell Douglas Estimates Y-12 Site ORVIP Site

3,094

784

3,270

4,268

.291

391

5,232

17,330
3,117

\section{9}

3,294

4,300

294

394

5,257

17,445 
The principal conclusion here is that the choice of site should have essentially no impact on the operating budget, except for small differences in overhead or fee. This seems reasonable and is in line with prior expectations.

$$
\text { c. Experimental Operation (Phase III) Cost Estimates (adjusted) }
$$

$\vdots \ldots$, Annual Costs (1980 \$, in thousands)

Item Y-12 Site ORVIP site

McDonne 11 Douglas and

Subcontractors' Staff

ORNL Staff

2,916

5,466 .

ORNL Staff

4,425

2,563

Spares and Supplies

752

752

Cryogens

106 .

106

Electricity

$821(640)^{\star}$

$919(1,250)$

TOTAL

$9,020(8,839) \quad 9,806(10,137)$

(*Figures in parentheses are $\underline{\mathrm{ORO}}$ estimates of electricity costs)

The basic conclusion here is that the base operating costs are estimated to be in the \$9-10 million per year range, not including. device improvements and upgrades, etc. Such costs are comparable to other fusion devices such as the Tandem Mirror Experiment (TMX), the Poloidal Divertor Experiment (PDX), Doublet III, etc.

The difference between the $Y-12$ and the ORVIP cost estimates is about $\$ 1.3$ million/ year. About $\$ 600,000$ of the difference is attributable to higher electricity charges as estimated by ORO. The remaining $\$ 700,000$ is due to indirect charges applied to McDonnell Douglas staff at ORVIP. This breakout is seen more clearly in factors $2-4$, below.

Factors Implying Higher Costs

$$
\text { at the ORVIP Site }
$$

Factor

Estimated Annual cost (1980 \$, in thousands)

1. Electricity is likely to be more expensive at ORVIP than at $\mathrm{Y}-12$ due to a demand charge billed by the local power company. These charges are negotiable for large users, but some increment will no doubt exist. $Y-12$ benefits from being part of a large DOE base load, and a demand charge is not applied............. +. +600 
2. Depreciation will be charged by McDonnell Douglas through their overhead structure. While not given explicitly in their proposal, a figure was given by McDonnell Douglas during the team visit to their headquarters. . . . +350

3. Labor costs for the additional McDonnell

Deuglas personnel would likely be somewhat higher due to fee and possibly higher overhead to maintain a separate administrative organization. Considering only fee differences, we would expect an increase of ......... . + +150

4. Property taxes would be due to the City of Oak Ridge and Anderson County. ORO estimates these to be............. . +200

Attempts will be made to negotiate terms with the local power company to make ORVIP electricity rates similar to those at $Y-12$, since DOE-funded activities on DOE-owned devices are involved at both locations. The depreciation is an allowable method for McDonnell Douglas to recover costs expended for the land and facility. Some of the taxes and expenses paid at the ORVIP site may be recoverable by the Government, although not necessarily OFE, in the form of reduced assistance payments to the City of Oak Ridge.

There are also factors to consider which could lead to higher costs at the $Y-12$ site. Some considerations are:

1. The $Y-12$ site can just barely accommodate EBT-P, and there is no room for future expansion. Even small modifications will depend on getting funds from a highly competitive General Plant and Projects budget.

2. The space allocated for $E B \mid-P$ in $Y-\mid ' 2$ will become unavallable to the fusion program for other future fusion activities. The cost of replacing that space is high at the $Y-12$ site, and is aggravated by the budgeting and schedule penalties that would derive from requesting a substilute line item facility.

3. At ORVIP, space to accommodate upgrades to EBT-P and/or construction of a large follow-on device will be available. Thus there will be not only new floor space available to the fusion program, but also there is room to expand as well.

Device upgrades are a normal part of the planned operation of any major fusion machine, and this will also be true for EBT-P, especially since it will be the only device of its kind. When such program considerations are taken into account, it is very likely that over the lifetime of the project, ORVIP will be the less costly site. After the first two to three years of operation, when the experimental plan calls for initiating major modifications to the machine, ORVIP appears to be much the preferable and more prudent site choice. 


\section{Potential Impact on Schedule.}

McDonne11 Douglas has proposed a 55 month schedule for either site. However, this proposed schedule assumes that project funding will be available in fiscal year 1982 and beyond as requested. As we all know, in the tight budget circumstances that have characterized the fusion program over the past several years, projects have not always received their requested funding. In such a case, the Y-12 schedule could slip substantially and seriously impact the costs through greater escalation. Since the ORVIP facility will be funded directly by McDonnell Douglas, however, that facility. schedule should be immune to DOE budget fluctuations that might otherwise adversely impact this critical item. Further, if device-related facility requirements are available soon enough, the potential exists for starting the ORVIP facility earlier than now scheduled. This would provide scheduling margin for installation work and enhance the probability of meeting the completion date. Since the ORVIP site would be dedicated solely to EBT-P, it would be decoupled from $Y-12$ construction and installation activities, and other competing operations such as experiments on EBT-S and the 86-inch cyclotron, thus eliminating the potential for such operations to impact the EBT-P construction schedule if in the future they -should receive high-priority emphasis.

In summary, whether budget perturbations occur or not, ORVIP offers the opportunity to accelerate the schedule slightly without cost penalties. In the case of perturbations, a greater potential for a significant slip exists at $\mathrm{Y}-12$.

\section{Efficacy and Viability of the Proposed Arrangement and the Interface.} With the EBT Program

Since the selection involves sites adjacent to each other, the weight carried by this consideration has substantially diminished relative to the other two. When allowance. was originally made for this consideration, it necessarily had to encompass all possibilities including sites very remote from 0ak Ridge.

It is expected that McDonnell Douglas will continue to be involved as a subcontractor on an existing major EBT-S effort, the direct ion-heating experiment, and with EBT reactor studies. MCDonnell Douglas and ORNL have worked and interacted well together in the past. We know of nothing that woul.d change or prejudice this past relationship. Thus, we foresee no major differences in the present category that would directly favor one site significantly over the other. However, it does seem that a new, highly visible facility at the ORVIP site would be a source of pride to the whole EBT community, a visible symbol of DOE's intentions for industry to play a major role in the fusion program, as well as an advancement of DOE's and Oak Ridge City's common goal of increasing the municipal tax base. 


\section{OFE Site Recommendation}

The relative advantages and disadvantages of the ORVIP site vis-a-vis the $Y-12$ site can be summarized as follows:

\section{ORVIP Site Advantages}

1. The new facility can be tailored to meet the specific needs of the EBT-P experiment and does not tie up presently utilized or available facilities. EBT-S could continue to operate as long as programmatically feasible.

2. There is room for expansion to accommodate upgrades to EBT-P or construction of the postulated next step device, which is not the case at $\mathrm{Y}-12$.

3. An autonomous, private facility would be immune to DOE budgetary fluctuations in providing general purpose facilities and cquipment support.

4. The probability of EBT-P project success should be enhanced by the high level of control that the contractor will have with the project at an autonomous site.

5. Operation with a relatively small, dedicated work force should provide better efficiency and flexibility. The required types of labor can be more closely matched to suit the type of activities than at $\mathrm{Y}-12$.

6. An URVIP site with an accompanying strong commitment by MCDcinnell Douglas would reinforce DOE's policy that industry play a major role in the EBT-P project and other fusion programs. The ORVIP site would give industry a greater role in the fusion program.

7. Locating EBT-P on property that would provide tax revenues to the City of Oak Ridge and help broaden the base of business activity would support DOE's policy of encouraging financial self-sufficiency and promoting local industrial development.

8. Access to the site for visits, exchanges, technical workshops, etc., would be excellent, as contrasted to the system at $Y-12$.

\section{ORVIP Sile Disadvanlages}

1. Support services (safety, security, shops, fire protection, etc.) during construction and operation may be difficult or awkward to provide.

2. Jurisdictional issues could arise depending on the degree to which Y-12 services are requested.

3. A separate administrative organization will be required. 
4. DOE and ORNL may not have full control over the facility design since the building and land will be donated.

OFE recognizes that at present a McDonnell Douglas infrastructure does not exist in Oak Ridge, and that to initiate the project at either site such a presence will have to be established. Mc.Donnell Douglas has given assurances that, should the firm be selected, the necessary personnel will be quickly moved to Oak Ridge.

When all of the above considerations are taken into account, the advantages to the Government in terms of potential for lower overall program costs, greater schedule control, and programmatic flexibility and interfacing, all favor the ORVIP site by greater or lesser margins. The more intangible factor of a Government versus a non-Government site and other program considerations also favor the ORVIP site.

In view of these findings and considerations, it is the recommendation of the Office of Fusion Energy that the EBT-P facility be approved for construction at the ORVIP site. We believe this recommerdation to be in the best interests of the Department of Energy, the Elmo Bumpy Torus program, and the fusion program generally.

This recommendation is based upon the assumption that a satisfactory contract can be negotiated between Union Carbide and McDonnell Douglas which will be acceptable to the Government. 